\title{
TEACHING ECONOMIC PRINCIPLES: ALGEBRA, GRAPH OR BOTH?
}

\author{
by David Zetland,* Carlo Russo, ${ }^{* *}$ and Navin Yavapolkul***
}

\begin{abstract}
We find that student performance on questions posed in the standard heterogeneous combination of algebraic direct demand and graphic inverse demand is significantly worse than their performance on questions posed in homogeneous combinations. Since this performance deficit persists with advanced students, it seems that economists' canonical presentation of demand may hinder, rather than help, learning. We recommend that Principles students begin with the homogenous, direct combination of algebra and graph before turning to the standard direct-inverse combination. This modification would create benefits on the extensive margin — reducing attrition from confusion — and intensive margin increasing comprehension for all students.
\end{abstract}

Keywords: Teaching methodology, Inverse demand, Graphs, Algebra, Undergraduate retention

JEL Codes: A22, B1

One of the first things students encounter in their first economics class (i.e., Principles of Economics) is the inverse demand curve, a graphical depiction of demand that inverts the algebraic expression of demand as a function of price so that price is on the vertical axis. This convention, as many professors know, can be confusing to students.

Is this confusion worthwhile or can we teach Principles in a different way that is beneficial (on net) students and for professors? In this paper, we explore the possibility of delaying the introduction of inverse demand and argue that the short and long run benefits from such a delay outweigh the costs.

We are not the first to examine the impact of presentation in economics teaching. Those who have looked into the broader question ("graphs versus algebra") make recommendations that appear to conflict. Thus we have Cohn et al. (2001, 2004) blaming graphs for students' confusion and Hey (2005) suggesting that graphs are better than alge- bra. These suggestions can be reconciled if we consider that students actually suffer from the mix of graph and algebra. But does the problem originate in the mixture itself or the way that graphic and algebraic forms are mixed? To answer this question, we compared several mixed forms: the standard heterogeneous combination of algebraic direct demand and graphical inverse demand and alternative algebra-graph combinations (direct-direct or inverse-inverse) in homogeneous forms. Because the inverse-direct mixture is the standard in economics, and we test students taking economics classes, we hypothesize that students will do at least as well answering questions posed in heterogeneous form as they do on questions in homogenous forms.

We reject this hypothesis. The 245 students who answered questions in our survey (see Appendix A) did worse on questions posed in heterogeneous forms than they did on questions posed in homogenous forms. Even worse, this performance gap

December 21, 2009.

* Zetland (corresponding author) is at the Department of Agricultural \& Resource Economics, University of California, Berkeley; dzetland@gmail.com.

** Russo is at the Università di Cassino - DIMET.

*** Yavapolkul is at the Department of Agricultural \& Resource Economics, University of California, Davis.

We thank Aslihan Arslan, Derek Berwald, Chris Dawes, Jennifer Lee, Brendan Livingston, Matthew Pearson, and Teddy Wong for surveying students; the 283 students who answered surveys; and Byeongil Ahn, David Colander, Robert Frank, Jennifer Keeling, Gorm Kipperberg, Joaquim Silvestre, Rich Sexton, Ed Taylor, session participants at the 2005 WAEA, and an anonymous referee for their helpful comments. This paper is derived from an earlier paper entitled "Is Inverse Demand Perverse?" 
does not disappear with exposure to economics. Students who had taken four or more economics classes got higher scores than students who were taking their first class, but still did worse on inverse demand questions.

These results are troubling for at least two reasons. First, they occur despite professors' attempts to help students overcome the widely-acknowledged problem of working with inverse demand. Second, they indicate that students of economics may face a serious and persistent barrier to understanding and using the tools of our profession.

Although we are not here to praise inverse demand, we are also not here to bury it. We understand the impressive utility of inverse demand and how this graphical convention is fundamental to economic analysis, teaching and communication. It is with this explicit benefit in mind that we recommend minimizing the cost of the inverse demand convention by delaying its use in Principles. Instead, we recommend that professors work with an algebra-graph pair in homogenous form (probably direct-direct) until students master analysis and manipulation with that technique. After that point, they can be taught to invert the algebra, draw inverse demand curves, and perform the analysis we use so often.

This suggestion will create new costs for the professor who will have to work with an (initially) unfamiliar format and for the students who will have to switch from one format to another, but we believe that the cost of "flipping axes" will be outweighed by the benefits to students (improved comprehension and manipulation skills) and professors (less student confusion). On a larger scale, better teaching will benefit the profession on the extensive margin (more students who continue in economics) and intensive margin (better understanding of economics among students who take one class or many).

In the next section, we describe how inverse demand is used and review the literature. In Section 2 , we report results indicating that students find it harder to use inverse demand. In Section 3, we discuss these results and how teachers can use them to improve their teaching.

\section{Teaching with Inverse Demand}

Most instructors teach Principles of Economics to undergraduates with algebra and graphs. Although the weight given to each component varies by instructor, some elements are universally accepted as "the standard." Perhaps the most famous is the inverted graphical presentation of demand in which the independent variable in the algebra (price) appears on the vertical axis. This presentation is called "inverse demand." See Figure 1 for an example and Appendix B for more background.

The left panel of Figure 1 shows our conventional view of demand, supply and surplus - the shaded area between the demand curve and vertical axis and above the flat marginal cost curve. The right panel moves these same curves so that demand is direct, i.e., at a price of zero, quantity demanded is 4 (the intercept on the vertical axis, now representing quantity). As price rises, the quantity demanded falls, and the direct demand curve slopes down until it hits zero at a price of 8 . (Note how this descriptive language matches our typical description of demand: a change in price leads to a change in quantity demanded.) Given a vertical supply curve (perfectly elastic at a price of zero), the equilibrium is at $P=2, Q=3$, and surplus is the area under the demand curve, to the right of cost and above the horizontal axis.

The inverse demand form used in all economic figures maintains consistency across various analytical goals and easily integrates with economic theory that's "naturally inverted," e.g., marginal utility and marginal cost. Beginning students may not experience this benefit because, first, inverse demand contradicts the mathematical convention of putting the independent variable on the x-axis; second, they must convert algebraic direct demand into graphical inverse demand; and third, they may not appreciate the future benefits of inverse demand. This imbalance does not make it easy for students to persist in economics, a major that - according to Hansen et al. (2001) - loses 95 percent of students who take Principles to other majors. ${ }^{1}$

Although students may have trouble learning with inverse demand, professors are unlikely to have trouble teaching with it. Since professors use inverse demand for their research and understand its future benefits, they are willing to tolerate its drawbacks. We wanted to know if professors adjusted their teaching to address students' potential confusion, and we asked for the opinions of professors at our university and subscribers to an internet discussion group on teaching economics. In response to the question ("If you're teaching with 

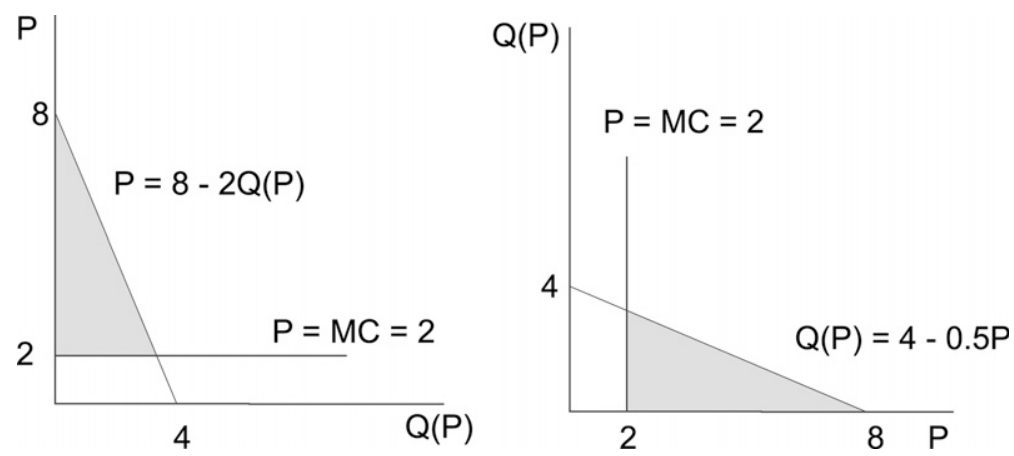

FIGURE 1. Algebraic and graphic depictions of inverse (left) and direct (right) demand functions, with perfectly elastic supply curves and consumer surplus shaded.

inverse demand graphs (exogenous $p$ on the vertical axis), have you noticed that students have difficulty with its 'counterintuitive standard?'"), most of the thirteen who replied acknowledged that some students had difficulty with it. They claimed that this cost did not keep them from using inverse demand because, first, "the smart students" had no trouble, and second, inverse demand has network externalities for students (taking later economics classes) and professors (teaching in a way that is compatible with their colleagues). These answers help us understand why professors prefer to use inverse demand (they may also use it to minimize their effort), but they do not qualify or quantify the merit of inverse demand relative to other presentation methods. For this comparison, we go to the literature.

From our reading, Cohn et al. (2001) are the first to mention the possibility that graphs may reduce learning by reducing the time available for other instructional methods. ${ }^{2}$ Cohn et al. (2004) find that the students who report problems with graphs (about half) also do worse on exams. Paradoxically, even more students (70 percent) feel that graphs are helpful. This latter result would not contradict the former result if students aspire to understand graphs without being able to use them very well. ${ }^{3}$ Cohn et al. conclude by questioning the value of adding graphs to algebra.

In contrast to these results, Hey (2005) advocates teaching with graphs but not algebra. We reconcile this apparent inconsistency with Cohn et al. by noting that students may be confused by the combination of algebra and graphs, not graphs or algebra per se. Elzinga (2001) writes basically the same thing — saying that "good teaching" (time, effort) is probably more important than the method of presentation.

Our notion agrees with Frank (2002, p. 460), who says "my point is not that the ideas themselves are useless. Rather, it is that, for beginning students, the effort required to master them could be far better spent in other ways." Hamermesh (2002) puts this in a broader context, advocating that Principles be taught as if students will not take another economics class. Instead, professors should teach the most important concepts with the least technical means possible. Comprehension is important: Dynan and Rouse (1997) find that "bad performance" reduces the chance that a student will pursue the economics major.

Other research fleshes out these results: Anderson et al. (1994) find that students with a background in calculus are less likely to drop introductory economics, but a background in algebra hardly matters. In Becker and Watts (2001), professors in Principles rate calculus, algebra and graphs as (respectively) "not at all," "moderately" and "extremely" important. These results are perhaps compatible if a calculus background is correlated with proficiency in algebra and graphs — something that Becker (1997) concludes. Ballard and Johnson (2004) also find a positive correlation between mathematical ability and performance in Principles.

\section{Survey of Students}

Economists are comfortable with the idiosyncracies of inverse demand, but we suspected that students were not. We surveyed 283 undergraduate students taking economics classes at our big 
university, and - after eliminating incomplete surveys - we ended up with 245 non-representative observations. ${ }^{5}$

In the survey (see Appendix A), we asked students to provide descriptive data and answer eight multiple choice questions divided into three parts. Part I's questions showed a demand graph and asked students to chose the equation that matched it (graph $\rightarrow$ equation). Part II's questions showed two demand equations and asked students to chose the equation for aggregate demand (equation $\rightarrow$ equation). Part III's questions showed two demand equations and asked students to chose the graph that matched aggregate demand (equation $\rightarrow$ graph).

Each part had questions and answers in direct and/or inverse form. ${ }^{6}$ If the forms were the same (e.g., direct graph to direct equation), we call that question "homogeneous." If the question used an inverse graph and direct equation, then it was "heterogeneous."7 Since economics students had seen inverse demand in the past, we hypothesized that they would do better with that form.

\subsection{Results}

Table 1 gives descriptive statistics and scores on survey questions, i.e., the percentage of the 245 students who got the question right. 73 percent of the students were economics majors, and their

\section{TABLE 1.}

Descriptive statistics and percentage shares of correct answers.

\begin{tabular}{lcccc}
\hline & \multicolumn{4}{c}{ Economics Classes } \\
\cline { 2 - 5 } & \multicolumn{1}{c}{ 2 or 3 } & $4+$ & All \\
\hline Number of Students & 64 & 79 & 102 & 245 \\
Average GPA & 3.02 & 3.10 & 3.19 & 3.12 \\
Econ Major (\%) & 53 & 70 & 88 & 73 \\
Part I (graph $\rightarrow$ equation) & & & \\
1: Inverse $\rightarrow$ Direct & 50 & 58 & 73 & 62 \\
2: Inverse $\rightarrow$ Inverse & 64 & 79 & 94 & 82 \\
3: Direct $\rightarrow$ Direct & 64 & 91 & 84 & 81 \\
Part II (equation $\rightarrow$ equation) & & & \\
4: Direct $\rightarrow$ Direct & 91 & 95 & 99 & 96 \\
5: Inverse $\rightarrow$ Direct & 91 & 95 & 95 & 94 \\
Part III (equation $\rightarrow$ graph) & & & \\
6: Direct $\rightarrow$ Inverse & 41 & 58 & 61 & 55 \\
7: Direct $\rightarrow$ Direct & 59 & 60 & 74 & 66 \\
8: Inverse $\rightarrow$ Inverse & 47 & 55 & 69 & 59 \\
\hline
\end{tabular}

exposure to economics varied (26 percent were in their first class; 42 percent had taken four or more classes). Statistics for GPA, enrollment in the major, and prior math experience are not noteworthy.

Our first result is that students usually do worse on questions that use heterogeneous algebra-graph combinations (questions 1 and 6) and better on homogenous combinations (questions 2, 3, 7 and 8). T-tests between question pairs indicate that students do significantly worse on question 1 than on questions 2 or 3 (p-values $<0.01$ ) and on question 6 than on question 7 ( $p$-value $<0.05$ ); the difference between questions 6 and 8 is not statistically significant. ${ }^{8}$ In other words, students do significantly better on three of four questions using homogenous forms than on questions posed in the standard heterogeneous combination of algebra in the direct form and graph in the inverted form - the combination that they have seen and used many times. These results lead us to reject the null hypothesis that students do the same or better on questions that use inverse demand. As a confirmation of the difficulty students have with inverse demand, observe that the success rate on question 6 for students in their first economics class is 41 percent, a result that is very close to the 33 percent success rate we would observe if they made random guesses.

Our second result is that student performance on homogeneous questions does not depend on the type of homogeneity (direct-direct or inverseinverse). ${ }^{9}$ From this result, we conclude that student performance is a function of homogenous presentation, not adherence to the mathematical standard (independent variable on the $\mathrm{x}$-axis) that appears with direct demand.

Our third result is that experienced students (4+ classes) do better than beginning students (first class) on algebra-graph combinations in questions $1-3$ and $6-8$ ( $p$-values $\leq 0.05)$. Unfortunately, this "learning" result does not extend to advanced students' facility with inverse demand. As with the entire sample, the 102 advanced students do worse on question 1 than on questions 2 and 3 and question 6 than on question 7 (p-values $\leq 0.05$ ). Figure 2 shows these performance gaps, first, $b e$ tween advanced and beginning cohorts, and second, within cohorts. We can therefore reject the hypothesis that students will master inverse demand if they are given enough time; rather surprisingly, they do better with novel homogeneous forms that they've never used. 


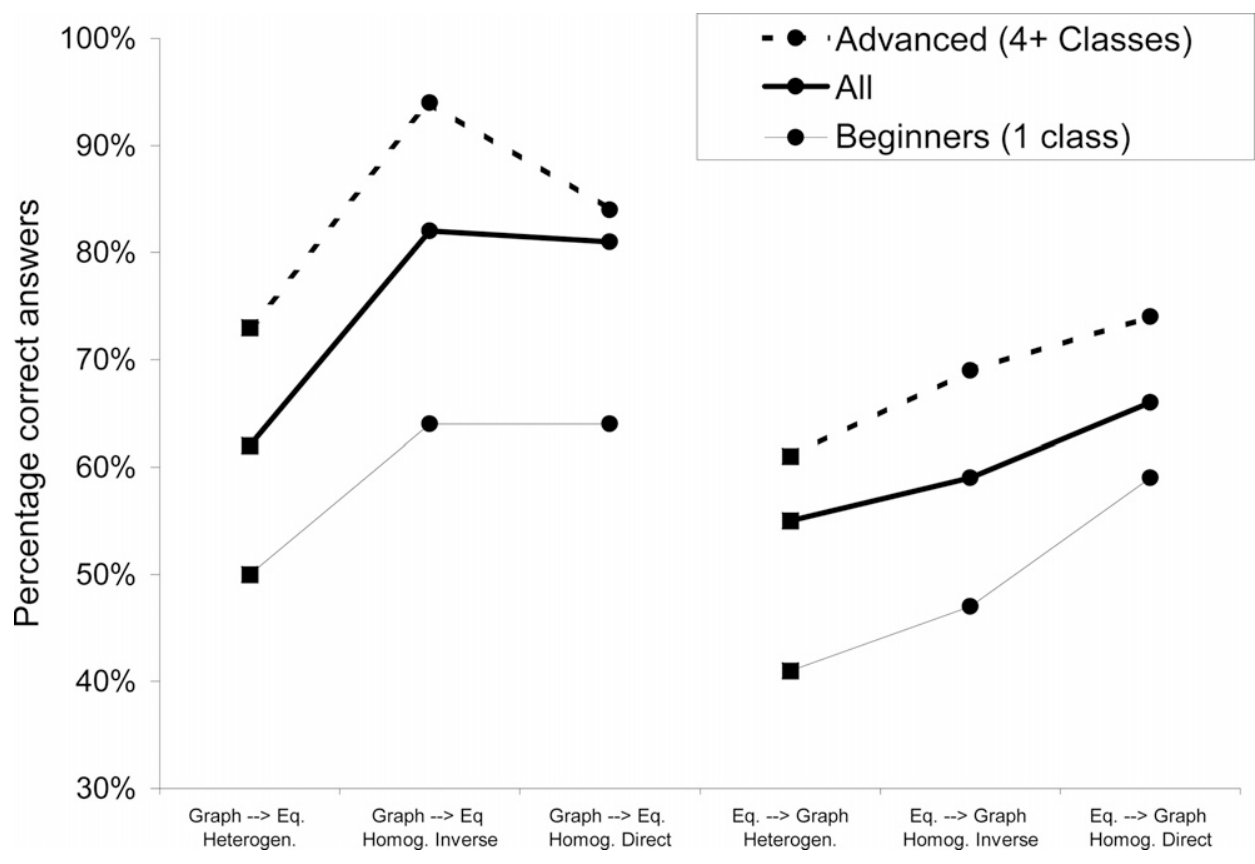

FIGURE 2. Performance by cohorts.

Our fourth result is that students do far better on algebra-only questions 4 and 5 than they do on the other questions. We ignore this result for two reasons. First, it is easier to answer questions that did not require one to translate between algebra and graphs (fewer steps and manipulations). Second, we cannot translate this result into a recommendation when few economists are willing to discard graphs altogether.

\section{Discussion}

According to our results, students do not have difficulty with graphs of inverse demand as much as a heterogeneous mix of graph and equation. ${ }^{10}$ A homogeneous presentation of the material, in contrast, increases student success.

Do these results suggest that we teach Principles differently? The answer depends on whether we are teaching Principles to find future economists or to spread basic economics to as many as possible. Professors might favor the former reason, i.e., they may like the way that inverse demand selects for the "right" types of thinkers — as it selected them. Further, professors may prefer inverse demand because they do not want to make an addi- tional effort to teach with a homogeneous form that is used neither in research nor in later economics classes.

While some students will doubtless prefer to learn with inverse demand (because they intend to continue in economics), many more students the ones who only take one or two economics classes - want to learn enough economics for basic literacy. ${ }^{11}$ If inverse demand prevents them from learning basic concepts (e.g., the law of demand), then they will not benefit from it. Even worse, inverse demand may lead the marginal student to take fewer economics classes or quit the major - results that teachers of economics probably want to avoid. Since these "non-professional" students are more numerous and a delayed introduction of inverse demand will not prevent economics majors from picking it up later, we merely recommend minimizing the transactions costs of inversion by inserting an intermediate step (homogenous form) so that students are able to learn the economics without tripping on the math. Once they master the direct demand combination of equation and graph, they can proceed to inversion. Put differently, we recommend learning two things (economics of a demand function and inverting algebra) serially, rather then in parallel. 
Professors, for example, could take the following steps:

(1) Start with direct algebraic forms of demand for an individual and supply for a firm. Combine these into a graph in the direct form to find the price-taking equilibrium. Total surplus is the area below (not to the left of) the supply and demand curves; see the right panel in Figure 1 for an example.

(2) Next, aggregate individual supply and demand functions to get aggregate demand and supply functions in both algebraic and graphic forms.

(3) After students are familiar with these functions, they can be inverted to clarify how price and quantity are simultaneously determined in the market.

(4) After students are comfortable with both forms, "naturally" inverse forms that treat quantity as the independent variable can be introduced and integrated, e.g., marginal cost (supply) and marginal utility (demand) curves.

(5) This last step can take place within Principles, improving student learning during the term while ensuring that they learn to use the "industry standard" before the end of the term and before they take other economics classes.

Although this procedure creates new costs for professors who have to work with an (initially) unfamiliar format and the students who have to switch from one format to another, we believe that the cost of "flipping axes" is outweighed by the benefits to students (improved comprehension and manipulation skills) and professors (less student confusion). In addition to these benefits are the benefits to the profession: a larger share of students moving from Principles to major in economics and an improved understanding of economics for all students.

\section{Conclusion}

If test performance is correlated with student comprehension, then the heterogeneous combination of (graphic) inverse demand and (algebraic) direct demand is a sub-optimal standard for students. In contrast to this result, we find that students do better with an homogeneous combination of graph and algebra. These results may explain why students have difficulty in Principles of Economics. Taking these results into account - while acknowledging the importance of inverse demand in advanced economics - we suggest that early instruction begin with graphs in a homogeneous form and that inverse demand be introduced later, when the benefits are greatest.

\section{Notes}

1. In any given year at our university, 10 percent of the students taking any economics class graduate with an economics degree. If students average five years to completion and all students taking classes graduated in the major, this share would be 20 percent. Thus, half the students taking economics classes graduate in another major, which is reasonable if economics is required in other departments. (Half is far lower than 95 percent reported in Hansen et al. (2001), but their figure is for Principles alone.) Our point is that inverse demand may push students away from economics at the margin.

2. They find that graphs do not have a negative impact when added to the end of a non-graph lecture, which confounds the value of graphs with the value of additional lecture time.

3. The authors report that students who think graphs are helpful do not perform better than those who do not.

4. He suggests, for example, that it is better to spend more time on opportunity cost and less time on short-run average cost curves.

5. 7.1 percent of all undergraduates at our university are in the economics or managerial economics major, but we did not select a random sample of these students. Instead, we gave the survey to students in eight discussion sections of four different economics classes; they had enrolled in or taken an average of 2.95 (median 3.00) classes in economics. We did not control for previous or current professors.

6. We designed the survey by randomly using the inverse or direct form for a set of simple demand equations. The answer choices were randomly sorted from a set which included the correct answer, a random answer, and an answer which came from an "upside down" 
method - i.e., as if the student did not invert when they should have or did invert when they should not have. Numbers in each question and question order were randomly determined. Although it is possible that some element in the construction of the questions may have favored some pattern of answers, that problem is never absent in test design.

7. We skipped the inverse equation-direct graph pair since it is rarely relevant in economics.

8. We assume that the answer for each question is distributed as multinomial with three possible outcomes per trial (student). $\left(y_{i}, p_{i}\right)$ describes the outcomes and probabilities for $i=1,2,3$, where 1 is the correct answer. A maximum likelihood estimator for $p_{k}$ given observed $\left(y_{1}, y_{2}, y_{3}\right)$ is simply the number of students who answer the $\mathrm{k}^{\text {th }}$ choice divided by the total number of students. Thus, we are implicitly assuming the same $a$ priori $p_{i}$ across all students. We constructed an asymptotic $\mathrm{z}$-statistic to test the difference in the rate of success between pairs of questions within parts for significance. We found the z-statistic with $Z_{\frac{a}{2}}=\frac{\hat{p}_{1}^{s}-\hat{p}_{1}^{t}}{\sqrt{\left(\frac{\hat{p}_{1}^{s}\left(1-\hat{p}_{1}^{s}\right)}{n_{s}}\right)+\left(\frac{\hat{p}_{1}^{t}\left(1-\hat{p}_{1}^{t}\right)}{n_{t}}\right)}}$ which is $\stackrel{a}{\sim}$ $N(0,1)$ and where $\hat{p}_{1}^{s}=\frac{y_{1}^{s}}{n_{s}}$ and $\hat{p}_{1}^{t}=\frac{y_{1}^{t}}{n_{t}}$ for $s \neq t$. Note that $\hat{p}_{1}^{s}$ and $\hat{p}_{1}^{t}$ indicate an estimated parameter for the probability of choosing the right answer (choice 1) in two different questions (e.g. direct-direct and direct-inverse). This allows us to test hypotheses on student performance across different types of questions.

9. T-tests fail to reject equality between question pairs $2 / 3,4 / 5$ and $7 / 8$.

10. Although it is possible that these results are derivative of our particular sample or testing method, we know of no reason why the results would not apply to the population taking Principles. Further, we are not concerned as to whether these results measure student success at math or economics. Facility with inverse demand may not be sufficient for success in economics, but it is certainly necessary.

11. The importance of teaching laypeople is increasing as Principles is offered earlier (e.g., as a required class for high school students) and more broadly (e.g., as a required class for interdisciplinary diversity among other majors in the US and faculties in Europe).

\section{References}

Anderson, G., Benjamin, D., and Fuss, M.A. (1994). The Determinants of Success in University Introductory Economics Courses. Journal of Economic Education, 25(2):99-119.

Ballard, C.L., and Johnson, M.F. (2004). Basic Math Skills and Performance in an Introductory Economics Class. Journal of Economic Education, 35(1):3-23.

Banaszak, R.A., and Brennan, D.C. (1983). Teaching Economics: Content and Strategies. Addison-Wesley Publishing Co., Menlo Park, CA.

Becker, W.E. (1997). Teaching Economics to Undergraduates. Journal of Economic Literature, 35(3):1347-1373.

Becker, W.E., and Watts, M. (2001). Teaching Economics at the Start of the 21st Century: Still Chalk-and-Talk. American Economic Review, 91(2):446-451.

Cohn, E., Cohn, S., Balch, D.C., and Bradley, James, J. (2001). Do Graphs Promote Learning in Principles of Economics? Journal of Economic Education, 32(4):299-310.

Cohn, E., Cohn, S., Balch, D.C., and Bradley Jr., J. (2004). The Relation between Student Attitudes towards Graphs and Performance in Economics. American Economist, 48:41-52.

Dynan, K., and Rouse, C. (1997). The Under-representation of Women in Economics: A Study of Undergraduate Economics Students. Journal of Economic Education, 28(4):350-68.

Ekelund Jr., R.B., and Hebert, R.F. (1975). A History of Economic Theory and Method. McGrawHill Book Company.

Elzinga, K.G. (2001). Fifteen Theses on Classroom Teaching. Southern Economic Journal, 68 (2):249-257.

Frank, R.H. (2002). The Economic Naturalist: Teaching Introductory Students How to Speak Economics. American Economic Review, 92 (2):459-462.

Hamermesh, D.S. (2002). Microeconomic Principles Teaching Tricks. American Economic Review, 92(2):449-453.

Hansen, W.L., Salemi, M.K., and Siegfried, J.J. (2001). Creating a Standards-Based Economics Principles Course. Working Paper 01-W05.

Hey, J.D. (2005). I Teach Economics, Not Algebra and Calculus. Journal of Economic Education, pages 292-304. 


\section{Appendix A: Economic Teaching Methods Evaluation}

Instructions. This evaluation is voluntary and confidential. Do NOT write any identifying information on this page! Please try to answer all questions in the time allowed.

\section{About You.}

Major: Are you now declared (or intending to declare) economics or managerial economics as your major? Please circle one... Yes No

Classes: Please circle all classes that you have taken or are currently taking:

\begin{tabular}{|c|c|c|}
\hline ARE100A & ARE100B & ARE155 \\
\hline ARE156 & ECN 1A & $\mathrm{ECN} 1 \mathrm{~B}$ \\
\hline & 101 & \\
\hline Math16B & Math21A & Mat \\
\hline
\end{tabular}

GPA: What's your cumulative GPA?

\section{Questions on Demand.}

Part I: Choose the multiple choice answer corresponding to the given graph (for the given axis combination)

(1) Choose the answer which matches the graph to the right $\left(Q_{d}\right.$ on X-axis).
(a) $Q_{d}=10-2 p$
(b) $Q_{d}=5-\frac{1}{2} p$
(c) $Q_{d}=5-2 p$

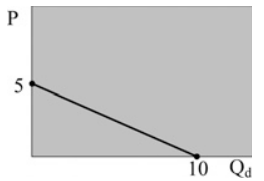

(2) Choose the answer which matches the graph to the right $\left(Q_{d}\right.$ on $\mathrm{x}$-axis).
(a) $p=7-\frac{7}{2} Q_{d}$
(b) $p=7-\frac{2}{7} Q_{d}$
(c) $p=2-\frac{2}{7} Q_{d}$

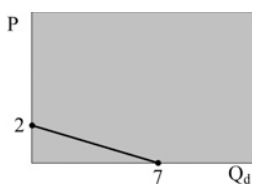

(3) Choose the answer which matches the graph to the right ( $P$ on $\mathrm{x}$-axis).
(a) $Q_{d}=3-\frac{1}{2} p$
(b) $Q_{d}=6-2 p$
(c) $Q_{d}=6-\frac{1}{2} p$

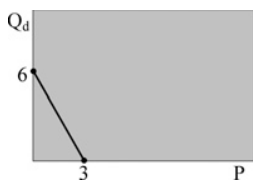

Part II: Given the following individual demand equations $\left(q_{1}, q_{2}\right)$ and market price $(p)$, circle the correct value of aggregate demand, $Q_{d}$ (where $Q_{d}=q_{1}+q_{2}$ ).

(4) If $q_{1}=3-2 p, q_{2}=3-2 p$ and $p=1$, then:
(a) $Q_{d}=4$
(b) $Q_{d}=2$
(c) $Q_{d}=3$

(5) If $p=4-3 q_{1}, p=4-3 q_{2}$ and $p=1$, then:
(a) $Q_{d}=4 \frac{1}{2}$
(b) $Q_{d}=2$
(c) $Q_{d}=7 \frac{1}{3}$

Part III: Circle the graph representing the aggregate demand function (for the given axis combination)

(6) If $q_{1}=4-p$ and $q_{2}=4-p$, then aggregate demand looks like $\left(Q_{d}\right.$ on x-axis):
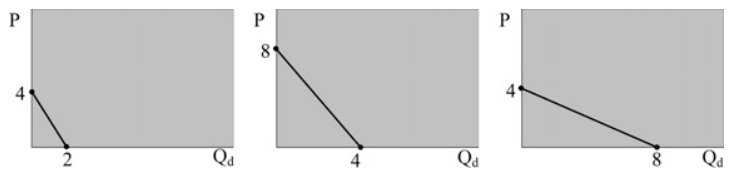

(7) If $q_{1}=3-p$ and $q_{2}=3-p$, then aggregate demand looks like ( $P$ on $\mathrm{x}$-axis):
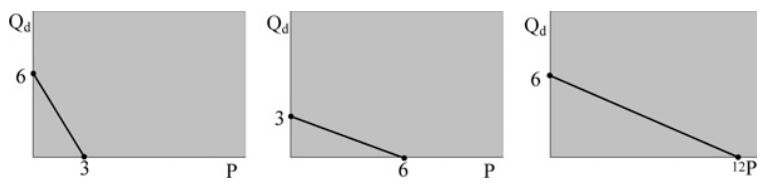

(8) If $p=3-5 q_{1}$ and $p=3-5 q_{2}$, then aggregate demand looks like ( $Q_{d}$ on x-axis):
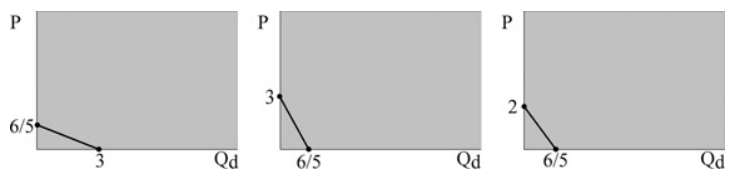

[ANSWERS: 1A, 2C, 3B, 4B, 5B, 6C, 7A, 8B.]

\section{Appendix B: The History and Use of Inverse Demand}

When Marshall wrote Principles of Economics, he put price on the vertical axis to show that price 
was a function of quantity. He maintained his $P(Q)$ notation - even when he knew quantity to be a function of price - for consistency. Léon Walras presented $Q(P)$ on the vertical axis because he took price as given in the market adjustment process. According to Ekelund Jr. and Hebert (1975), "the basic difference between Walras and Marshall, with regard to the market adjustment mechanism, is that Walras regarded price as the adjusting variable when markets are in disequilibrium whereas Marshall focused on quantity as the adjusting variable in the same circumstances" [p. 314].

Today, economists mix algebraic traditions but stay with Marshall's graphical standard. In Teaching Economics, for example, Banaszak and Brennan (1983, pp. 62-63) define demand as "the quantity of a product that individuals are willing and able to buy at each and every price during some specified period of time." As an example, they set out a demand schedule which shows the quantity of pizza demanded at each price, i.e.,

\begin{tabular}{cc}
\hline Price per Slice & Quantity Demanded \\
\hline$\$ 1.00$ & 200 \\
0.80 & 400 \\
0.60 & 600 \\
0.40 & 800 \\
0.20 & 1,000 \\
\hline
\end{tabular}

This table is then translated into a demand curve which "expresses the relationship between price and quantity demanded" with price on the vertical axis, i.e.,
In addition, Banaszak and Brennan mix and merge Walras and Marshall in a way that obscures their separate views. On page 69, they write:

\section{Supply and Demand: Price Determination}

The interaction of the buying decisions of consumers and the selling decisions of producers determines the market price of an item. If the producers ask a price that the consumers feel is too high, the product will not sell. Accordingly, the price must be lowered until the market price is achieved. At this price, the quantity of the good or service that producers are willing to produce and supply to the market is identical with the quantity consumers are willing and able to buy. Economists call this price the equilibrium price, meaning the price that brings balance.

If the price at which a good or service is offered to the public is above the equilibrium price, producers will be willing to supply more of the commodity but buyers will buy less. The result is an excess in supply (a surplus). If the price is below equilibrium, the producers are willing to supply less of the commodity but buyers are willing to buy more. The result is a temporary excess of demand (a shortage).

In the first paragraph, prices adjust until $P_{d}=P_{s}$ (and quantities balance). In the next paragraph, price is given, $Q_{d} \neq Q_{s}$, and a surplus or shortage results.

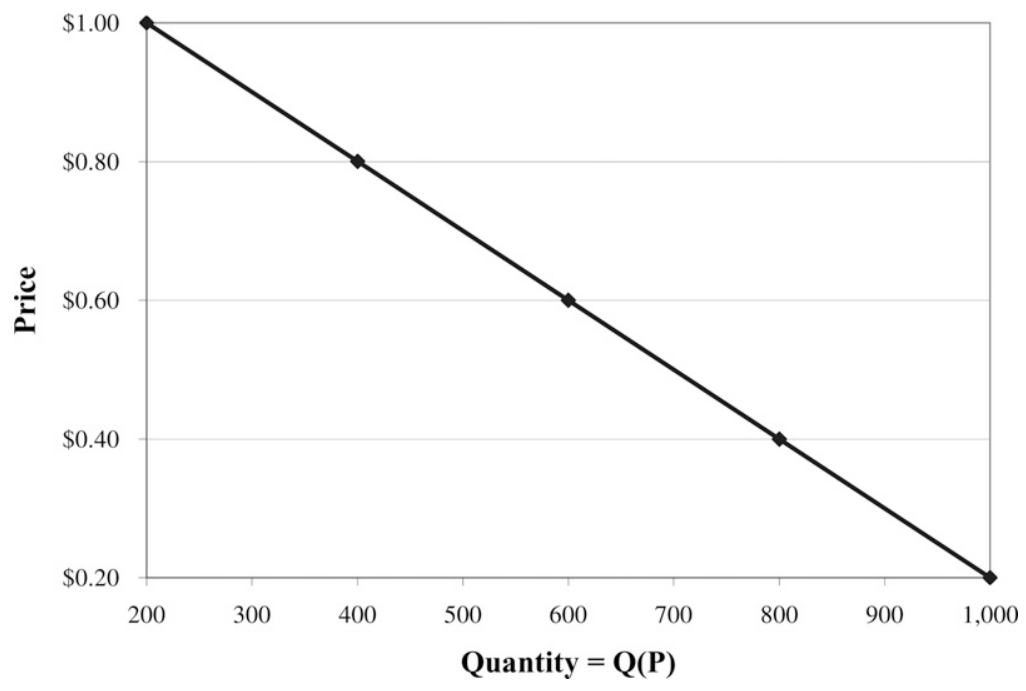

